\title{
Assessment of effectiveness expenditures of pharmacy information system in medication-related services in hospitals of Iran
}

\author{
Razieh Mirzaeian ${ }^{1}$, Sakineh Saghaeiannejad Isfahani ${ }^{2}$, Mahmoud Mobasheri ${ }^{3}$, \\ Javad Sharifi $\operatorname{Rad}^{4,5,6 *}$
}

\begin{abstract}
${ }^{1}$ MSc in Health Information Management.
Research Assistant, Deputy of research and technology Shahrekord University of Medical Sciences. Shahrekord, Iran

${ }^{2} \mathrm{MSc}$ instructor, Health Management of Economic Research Center, Isfahan University Medical Science. Ph D. Student of educational and administration. University of Sciences, Department of Health Information Technology, Isfahan, Iran

${ }^{3} \mathrm{Ph} . \mathrm{D}$ in Epidemiology, Associate Professor, Department of epidemiology and bio-statistics, Faculty of health, Shahrekord University of Medical Sciences, Shahrekord, Iran ${ }^{4}$ Department of Pharmacognosy, Faculty of Pharmacy, Zabol University of Medical Sciences, P.O. Box 61615-585 Zabol, Iran ${ }^{5}$ Zabol Medicinal Plants Research Center, Zabol University of Medical Science, P.O. Box 61615-585, Zabol, Iran

${ }^{6}$ Cereal Health Research Center of Zabol, Zabol University of Medical Sciences, P.O. Box

61615-585 Zabol, Iran
\end{abstract}

Received: 23 November 2013

Accepted: 15 December 2013

\author{
*Correspondence to: \\ Dr. Javad Sharifi Rad, \\ Email: javad.sharifirad@gmail.com
}

(C) 2014 Mirzaeian R et al. This is an openaccess article distributed under the terms of the Creative Commons Attribution NonCommercial License, which permits unrestricted non-commercial use, distribution, and reproduction in any medium, provided the original work is properly cited.

\begin{abstract}
Background: On average, $40 \%$ of the gross income of each country is devoted to the health care with medication expenditures accounting for $19 \%$ of the total expenses. Less than $1 / 4$ of the medication expenditures is allocated to the inpatients department. The measures taken regarding the management of expenditures when selecting and implementing the strategies for managing medication expenditures have made the pharmacists to take the quality issues as well as the safety of the patients into account.

Methods: The present research intends to explore the expenditures of effectiveness of Pharmacy Information System (PIS) for the medication services as far as effectiveness of delivered services is concerned in some selected hospitals in the city of Isfahan, Iran. The present research of applied and descriptive-analytical nature was conducted in the hospitals in the City of Isfahan, Iran. Instruments used for collecting data included self designed checklist conforming to the guidelines of the American Society of Health-System Pharmacists (ASHP) the validity of which was assessed based on the viewpoints of the expert professors. The data gathered by interview and observation methods. Then, they were analyzed using non-parametric tests of Mann-Whitney and the Wilcoxon tests and SPSS software (11.5 version).

Results: The highest rate of the expenditures of the effectiveness of the pharmacy information system belonged to the teaching hospitals with a mean score of $48.5 \%$, while the lowest rate was found to be for private hospitals with a mean score of $28.1 \%$. Based on the findings of the Wilcoxon test, no statistically significant difference was observed among the hospitals in terms of effectiveness-related expenditures.

Conclusions: Given the results of the study, it can be noted that a successful plan for managing the medication-related expenditures must be information-based.
\end{abstract}

Keywords: Effectiveness expenditures, Medication services, Pharmacy, Pharmacy information system

\section{INTRODUCTION}

Nowadays, in the nations which possess an advanced health system, the pharmacies of the hospitals and their pharmacist staff play a critical role in the medication therapy process. ${ }^{1}$ The pharmacy department of the hospital must interact with other departments of the hospital through internal computer network so as to have a complete supervision over the status of the patients and 
measures taken for them besides tracking the medication therapy process and controlling over the logical use of drugs. ${ }^{2}$ Such an association may be established with admission and discharge departments (to access the admission and discharge data and medical profile of the patients), ${ }^{3}$ accounting department (to pay the invoices of the medications), ${ }^{4}$ nursing department (to warn about the omission of the medication) and laboratory department (to regulate drug dosage). ${ }^{5}$ Most data systems available in the pharmacies produce some reports regarding the medication usage pattern in the hospital and the expenditures of the dispensed medications. ${ }^{6}$ When selecting factors reducing the medication-related expenditures, first purchase of the drugs and its management must be taken into account since medication costs are a part of earned costs.

Johnson and Bootman (1995) reported that in their decision-analysis model, applied for exploring the medication-related complications, have estimated the costs of drugs' side effects and their resultant mortality at about $\$ 6.76$ billion (8). In 2003, Canada has allocated over $\$ 16$ billion i.e. $\$ 500$ per capita for medication expenditures and now there has been a $10 \%$ increase in investment in this section of health care system in this country. ${ }^{9}$ Based on the results of other studies carried out by Aspidan and Batman (2006), the rate of medications' side effects have been estimated to be 380,000-450,000 every year accounting for $\$ 3.5$ billion of the hospital's expenditures. ${ }^{5}$

Successful drug formulary management depends on the accuracy of the factors and evidence used for making decision about inclusion or exclusion of the drugs in the formulary. American Society of Health-System Pharmacists advises using formulary management in the hospital context to manage the quality and expenditures of the medications in order to optimize the patient care by using appropriate, healthy and cost-effective drugs. USA has invested about $16 \%$ of its national income on the health care in 2007. Besides USA, in France, Switzerland, Germany and Saudi Arabia about $11 \%$, $8.10 \%, 10.4 \%$ and $4 \%$ of the national income has been devoted to the health care services, respectively. It is noteworthy that medication costs currently account for $10 \%$ of the total health-related costs in all the nations. ${ }^{10}$ All medication inventories must be regularly checked and tagged to ensure the absence of expired products. As well as storage conditions which may lead to an increase in the medication wastes and the order of storing drugs that are effective in managing medication errors must be evaluated and modified. ${ }^{11}$

The approved drug products with common use must be purchased, stored and be available in sufficient amount to meet the requirements of the existing patients. ${ }^{12}$ Supporting the medication purchase process and producing the list of required medications to be purchased are among the capabilities of the Pharmacy Information System (PIS). ${ }^{13}$
Maintaining internal inventories of all drug products, PIS can assist the management of pharmacies' inventories. When the amount of one drug is below the normal level, flags and alerts come up in the system producing an electronic request based on which drug products are supplied from a validated drug producer company in sufficient amount. ${ }^{6}$

Using barcodes for validating dispensing proper medication to the proper patient at proper time can lead to a decrease of approximately as many as 500,000 in side effects and integrative errors resulting in a $\$ 93$ billion saving in the expenditures as far as patients' pain and suffering and wasted work time are concerned. ${ }^{14}$ Averagely, $40 \%$ of the gross income of a nation is devoted to the health care and medication costs account for $19 \%$ of the total expenditures. Less than $1 / 4$ of the drug costs is related to the inpatient department. ${ }^{15}$ Some medication expenditures amount to $\$ 15,000$ every month. The costs required for some medications have amounted to almost $\$ 54$ billion in 2008, while it has been predicted that it may increase to $\$ 99$ billion until the end of 2010 . $^{16}$ According to World Health Organization' estimations, $10 \%$ of the world medications are of medical type with $\$ 75$ billion sale in 2010. ${ }^{17}$ From 1998 to 2002, the average yearly costs for medications have been $14.54 \%$, $9.7 \%$ and $1.12 \%$ for USA, Britain and Australia, respectively. ${ }^{18}$

Numerous strategies have been adopted for managing medication-related costs in the hospitals and health system some of which are relatively simple and specific usable in the pharmacies, while some other are complex to some extent requiring a higher level of strategic contribution and collaboration on the part of hospital authorities. Successful management of the medication expenditures requires due attention and integration of all the existing methods and solutions. Due to the complex nature of the medication costs management actions and their diversity, it is of high importance that when selecting and implementing the strategies of medication costs management, the pharmacists take the quality of the care as well as the safety of the patients into consideration. Limitations and measures adopted for decreasing medication-related costs should not constrain the capabilities of the health system for delivering the best care to the patients. ${ }^{7}$

Accordingly, given the role of advanced technology as the highest priority for the supremacy of the electronic health system on the pharmacy performance ${ }^{13,19}$ and the capabilities of PIS in improving the quality of production, distribution, maintenance and control of the drugs as well as the significance of information for the efficient and effective management of the pharmacy services by managing drug costs, the necessity of the evaluation of PIS referring to the standards of the American Society of Health-System Pharmacists in terms of the registry of drugs costs, updating the price of the drugs, calculating the drug purchases and managing the drug inventory as 
well as automatic warning against the expired drugs all provide some evidence on the existing necessity to conduct such studies.

\section{METHODS}

This study is of applied analytical-descriptive crosssectional nature. The research population includes the PISs in use by 10 teaching, 7 private and 2 socialinsurance hospitals. Data collection instrument was a self-designed checklist including 44 informational components based on informational guidelines of the American Society of Health-System Pharmacists. This checklist was compiled in terms of the registry of drugs information and costs, the automatic registry of the cost of the inpatients' and outpatients' orders, periodical needs assessment of drug purchase, calculation of the costs of the purchased and distributed drugs, estimation of the drug inventory based on the medication costs. The content validity of the checklist was assessed by reviewing the previous studies and colleting the views of the supervisor and advisor professors as well as other practitioners and experts of the Computer Sciences, the professors of the Health Information Management field and pharmacists. To collect the data, the researcher visited the hospitals in person and besides observation, conducted some face to face interviews with the authorities and users of the PIS. After final control, the data were put into SPSS software to be analyzed. Descriptive statistics such as frequency and relative frequency were the used methods for analyzing the data. The degree of meeting the standards of the American Society of Health-System Pharmacists was assessed using non-parametric Mann-Whitney U and the Wilcoxon tests. In fact, it was investigated how the standards in question were met in the PIS and drug inventory information system in terms of registry, calculation and report of drug costs in terms of the type of hospitals. The hospitals were analyzed and compared accordingly.

\section{RESULTS}

Among 10 teaching, 7 private and 2 Social Insurance hospitals in question, the PIS used was manual and computerized for $26.31 \%$ and $73.69 \%$ of the hospitals, respectively.

Data represents the comparison of the mean score percentages for the registry of drug costs information, the calculations of the purchased and distributed drugs, the estimate of drug inventory based on the standards of the American Society of Health-System Pharmacists for the hospitals in question (Table 1). According to KruskalWallis test, the mean scores for the registry of drug costs data, the calculation of the costs of the purchased and distributed drugs, the estimate of the drug inventory in the PIS of different hospitals at the level of significance of $10 \%$ were significantly different $(\mathrm{P}$ value $\leq 0.06)$. However, the pair-wise comparison of the hospitals in question based on Mann-Whitney test's mean scores for registry of medication-related expenditures shows there is no statistically significant difference between teaching and private hospitals and private and social-insurance hospitals at a significance level of $10 \%$ with a $p$ value of 0.82 and 0.13 , respectively. On the contrary, there is statistically significant difference between teaching and social insurance organization associated hospitals at a level of significance of $5 \%$ ( $p$ value $\leq 0.02$ ) (Table 2 ).

Table 1: The comparison of the mean scores percentages for the registry of medication-related expenditures data based on the standards of ASHP among the hospitals in question.

\begin{tabular}{|lllll|}
\hline Type of Hospitals & Number & MS (\%) & SD & $\chi$ test \\
\hline Teaching & 10 & 48.5 & 0.59 & 5.45 \\
\hline Private & 7 & 28.1 & 0.66 & 5.45 \\
\hline Social Insurance & 2 & 46.5 & 0 & 5.45 \\
\hline Total & 19 & 40.75 & 0.69 & --- \\
\hline *SE: Standard deviation; MS\%: Mean score\% & & \\
\hline
\end{tabular}

Table 2: The comparison of mean scores percentages for the registry of medication-related expenditures data based on the standards of ASHP among the hospitals in question.

\begin{tabular}{|llllll|}
\hline Teaching hospitals names & MS $(\%)$ & Private Hospitals Names & MS(\%) & $\begin{array}{l}\text { Social insurance } \\
\text { hospitals names }\end{array}$ & MS (\%) \\
\hline Nour and Ali Asqar & 71.11 & Clinic Khanevadeh & 45.00 & Shariati & 46.67 \\
\hline Isa Ibn Maryam & 51.11 & Sepahan & 17.78 & Qarazi & 40.97 \\
\hline Imam Mousa Kazem & 66.67 & Sa'di & 22.22 & Total & 43.82 \\
\hline Chamran & 45.00 & Mehregan & 17.50 & & \\
\hline Beheshti & 22.22 & Sina & 13.33 & \\
\hline Kashani & 53.89 & Zahra -e-Marzieh & 22.22 & \\
\hline Feiz & 31.11 & Total & & \\
\hline Al-zahra & 56.11 & & & \\
\hline Amin & 46.67 & & & \\
\hline Seyyed Al-Shohada & 42.22 & & & \\
\hline Total & 48.11 & & & \\
\hline *SE: Standard deviation; MS\%: Mean score\% & & & & \\
\hline
\end{tabular}


Table 3: The comparison of mean score percentages for the registry of medication expenditures data based on the standards of the ASHP in terms of the type of used PIS (local software).

\begin{tabular}{|llll|}
\hline PIS names & Covered hospitals number & MS (\%) & SD \\
\hline Hamedan Sayan Rayan Ekbatan & 6 & 46.85 & 18.88 \\
\hline Kowsar (Old version) & 2 & 44.44 & 31.42 \\
\hline Kowsar (New version) & 1 & 31.11 & 0 \\
\hline Pouya Samaneh & 2 & 39.16 & 23.96 \\
\hline Loh Gostar & 4 & 34.58 & 20.09 \\
\hline Rayavaran Toseeh & 1 & 22.22 & 0 \\
\hline Modiriat Amar & 1 & 42.22 & 0 \\
\hline Social Insurance Services & 2 & 46.66 & 11.09 \\
\hline *SE: Standard deviation; MS\%: Mean score\% & & \\
\hline
\end{tabular}

\section{DISCUSSION}

Given the findings of the study, it can be said that regarding observing the standards related to the medication expenditures data, calculation of the costs of purchased and distributed medications, estimation of the inventories based on the standards of the ASHP, the hospitals in question with a maximum mean score of 48.5 are remarkably far from optimum condition. It is worth mentioning that Lada and Delago (2007) have carried out several studies on the significant decrease in the costs in the Emergency departments using PIS. As level 1 Trauma Center has predicted, the annual decrease in the medication costs using PIS in the Emergency department may be about $\$ 3.589 .328$. $^{20}$

In 1996, it was found that "managing hospital drug utilization and expenditures" ranks $20^{\text {th }}$ in the priority list of "Chief Executive Officers" of the hospitals. Repetition of the survey in 2000 showed that this item has elevated to the fourth position. The results of this survey also revealed that among the primary challenges of hospitals, medication costs and technology for decreasing the expenditures and repays ranks $2^{\text {nd }}$. The chief executive officers reported that medications are one of the significant and foremost opportunities for decreasing the expenditures. A successful plan for managing drug expenditures must be information-based. The pharmacy management must apply the available data to achieve a high efficient and effective management through managing resources, purchase center and financial center. ${ }^{7}$ The results of John's study entitled "The Advantages of Pharmacies Equipped with Computer System in the Novel Charleston Hospitals (1983)" revealed that calculating the medication dosage for the outpatients, the computer system has increased the work load of the pharmacies on the one hand and decreased the time required for preparing the orders up to $20 \%$ during a 2-year period. $^{21}$

The capabilities of PIS play an essential role in mitigating medication expenditures. To control the drug-related costs, this system must: a. Specify the list of medications required for every patient every day;

b. Determine their transformation and exchange rate;

c. Specify the items covered by the insurance companies;

d. Control the compliance of the performed actions with the contracts;

e. Determine the in-varied or edible drugs;

f. Balance the medication expenditures according to the volume (e.g. the cost devoted for each patient, discharge and etc.)

g. Control the balanced volume based on expenditures related to the rank and category of the drug (e.g. antibiotics, inhaling drugs and etc.).

h. Determine the descending order of the purchased items during the time. ${ }^{7}$

The maximum mean score for meeting the standards of ASHP for controlling the expenditures and effectiveness of medication services in the existing PIS has been about $46.66 \%$ which is very far from optimum condition. The analyzer system is responsible for checking all the data and maintaining them against transferring systems for automatic prescription systems, ADI systems, paying hospital bills and purchase systems are directly responsible.

Medication related informational resources are considered as essential tools for health care organizations. Medication informational resources are required for taking documentary medication-related measures in an effective and safe way. The medication informational requirements, personnel's resources and capabilities in using medication informational systems must be evaluated at least yearly to ensure the satisfaction of patients' care requirements. ${ }^{16}$ A $66 \%$ increase in the yearly expenditures for order-based medications and edible solid drugs in Canada represents a $\$ 42.4$ billion increase. Such a growth in investment in short-time requires accurate and due attention. Researchers in field of medication usage analysis must determine whether these conditions reflect enhancement of the quantity of the health related desirable results from the medications or merely covers an increase in the expenditures. ${ }^{22}$ 


\section{CONCLUSION}

As the demand for one specific medication product increases unpredictably or its production capacity increases or when a new parameter emerges for a productive drug i.e. the medication usage trends change in response to a new form of medication or a significant disease becomes prevalent or if unforeseen conditions come up, or when the raw materials are not available or production is a prolonged or time-consuming process, the shortage of a medication may be prolonged. The pharmacist has some responsibilities for how to supply medication tools, if such tools have a direct effect on the medications and care process. To put it better, the pharmacist is directly responsible for controlling the supply of medication-related tools and instruments.

\section{Funding: No funding sources}

Conflict of interest: None declared

Ethical approval: Not required

\section{REFERENCES}

1. Saghaeian Nejad S, Mirzaeian R, Habibi M. Assessment of Pharmacy Information Performance in Selected Hospitals in Isfahan City During 2011.Jundishapur J Nat Pharm Prod. 2013;8(1):3-9.

2. American Society of Health system pharmacist, s. ASHP statement on the pharmacist $s$ Rolr in Informatics. 2007;64:200-3.

3. American Society of Health-System Pharmacists. ASHP Guidelines on Remote Medication Order Processing: Access to Drug Information and Hospital Policy Resources. Am J Health-Syst Pharm. 2010;67:672-7.

4. Saghaeiannejad Isfahani S Raeisi A R, Ehteshami A, Janesari H, Feizi A, Mirzaeian R. The Role of Evaluation Pharmacy Information System in Management of Medication Related Complications. ACTA INFORM MED. 2013Mar;21(1):26-29.

5. Eharles D, Mahoneychristine M, et al. Effect of an integrated clinical information system on medication safety in a multi- hospital setting. Am J HealthSytem Pharm. 2007;64:1969-77.

6. Lilian Burke, Barbara Weill. Information Technology for Health Professions. 2003:205. Available at www. amazon.com.

7. American Society of Health System pharmacist's. ASHP Guidelines on Medication Cost Management Strategies for Hospitals and Health systems. AJHP. 2008;65:1368-84.

8. Johnson JA, Bootman JL. Drug-related morbidity and mortality: a cost of illness model. 1995;155:1949-56. Available at: http://www. gigapedia.com.

9. Steven Morgan. Drug Spending in Canada Recent Trends and Causes. Medical Care. 2004;42(7)63542.
10. Mohammed S. Alsultan. The role of pharmacoeconomics in formualry decision making in different hospital in Riyadh, Saudi Arabia. Sauidi Pharmaceutical Journal. 2011;19:51-5.

11. American Society of Health System pharmacists. ASHP Guideline: Minimum Standard for Pharmacies in Hospitals. AJHP. 1995;1(52):270711.

12. American Socity of Health System pharmacists. ASHP Guideline Minimum standard for pharmaceutical services in Ambulatory care. Am J Health- Syst Pharm. 1999;1(56):1744-53.

13. Fassett, Kaffe. Computer Application in Pharmacy. European Union:William and Wilkins.1986.

14. Skiba M. Strategies for Indentifying and Minimizing Medication Errors in Health Care settings. The Health Care Manager. 2006;25(1):70-7.

15. Sabin Vogler, Claudia Habel, Christine Leopold, Jan Mazag T, Simone Morak , Nina Zimmermann , Romana Landauer. PHIS, Pharmaceutical Health Information system, Hospital pharmacy report commissioned by the European Commission. Executive Agency for Health and Consumer (EAHC) and the Australia Federal Ministry of Health (BMG). 2010:18-19.

16. American Society of Health system pharmacist, s. ASHP statement on confidentiality of patient Health Care Information. Am J Health Syst Pharm. 2009;66:411-12.

17. Thomas A. Hemphill. PhRMA and the Partnership for Prescription Assistance: a win-win situation? Corporate Governance Journal. 2007;7(3):278-87.

18. June M. Tordoff, Pauline T. Norris, David M. Reith. Managing Prices for Hopital Pharmaceuticals: A Successful Strategy for New Zealand?. ISPOR. Value in Health Journal. 2005;8(3):201-8.

19. Abedelhak Mavet, Grostick Sara, Hanken Mary Alice, Jacobs Ellen, editors. Health Information of Management a strategic Resource. 2nded. United states: W. B. saunders company. 2002.

20. Christopher J. Edwards, Karalea D. Jasiak, Daniel P. Hays. Clinical pharmacists Coming Soon to an Emergency Department Near You!. Advanced Emergency nursing Journal. 2010;32(2):122-6.

21. John T. Nazzaro, John F. Beary. Benefits of a Computerized Phamacy. JAMA. 1983;249:3302-3.

22. Al-Dhawailie. Inpatient prescribing errors and pharmacist intervention at a teaching hospital in Soudi Arabia. Sauidi Pharmaceatical Joural. 2011;19:192-5.

doi:10.5455/2319-2003.ijbcp20140211

Cite this article as: Mirzaeian R, Isfahani SS,

Mobasheri M, Rad JS. Assessment of effectiveness expenditures of pharmacy information system in medication-related services in hospitals of Iran. Int J

Basic Clin Pharmacol 2014;3:100-4. 